\title{
A adolescência escrita em blogs ${ }^{1}$
}

\section{Adolescence as viewed through blogs}

\author{
Priscilla CAIROLI ${ }^{2}$ \\ Gabriel Chittó GAUER
}

\begin{abstract}
Resumo
A escrita em blogs, na adolescência, apresenta-se como um fenômeno contemporâneo crescente. Este artigo tem como objetivo refletir sobre a escrita em blogs na constituição do sujeito adolescente, em uma perspectiva psicanalítica. O tema foi abordado por meio de uma revisão de literatura que teve como ponto de partida os legados de Freud sobre a escrita, seguindo até psicanalistas contemporâneos que pesquisam sobre esta temática. Em seguida, foram assinaladas questões relacionadas às mudanças vividas na adolescência, enquanto evento subjetivo, em um enlace com a escrita neste momento da vida. Por fim, foram apontadas algumas considerações sobre a escrita na internet e sobre os blogs.
\end{abstract}

Unitermos: Adolescência. Blogs. Escrita. Internet.

\begin{abstract}
The use of blogs, as a place for adolescents to write about their experiences, is a growing contemporary phenomenon. The purpose of the present article is to analyze the writing contained in blogs in the make-up of the adolescent subject, from a psychoanalytic perspective. The topic was approached through a review of relevant literature starting with Freud's legacies about writing, moving on to the work of contemporary psychoanalysts who are researching the subject. Afterwards, issues are presented related to changes experienced in adolescence, as a subjective event, coupled with the writing at that point of time in their life. Finally, some considerations are proposed about writing on the internet and about blogs.
\end{abstract}

Uniterms: Adolescence. Blogs. Internet. Writing.

Na cena contemporânea, a revolução eletrônica e a internet têm possibilitado, além de novas formas de comunicação, meios de expressão e produção da subjetividade. No momento em que o suporte textual passa a ser a tela do computador, surge uma escrita e uma leitura online. Existem várias ferramentas disponíveis na web, tais como correio eletrônico, messenger, orkut, skype, chats, blogs, videoconferências, entre outros.

Neste artigo de revisão teórica, lança-se um olhar sobre a escrita adolescente em blogs, produções culturais da atualidade cuja prática tem sido crescente e merece uma investigação mais aprofundada. Foram

\section{$\nabla \nabla \nabla \nabla$}

1 Artigo elaborado a partir da dissertação de P. CAIROLI, intitulada "A escrita em blogs na constituição do sujeito adolescente". Programa de Pós-Graduação em Psicologia, Pontifícia Universidade Católica do Rio Grande do Sul, 2007. Apoio: Coordenação de Aperfeiçoamento de Pessoal de Nível Superior.

2 Pontifícia Universidade Católica do Rio Grande do Sul, Faculdade de Psicologia, Programa de Pós-Graduação em Psicologia. Av. Ipiranga, 6681, Prédio 11, $9^{\circ}$ andar, Sala 931, Partenon, 90619-900, Porto Alegre, RS, Brasil. Correspondência para/Correspondence to: P. CAIROLI. E-mail: <pricairoli@gmail.com>. 
realizados alguns estudos a respeito dos blogs: Lemos (2002), Recuero (2003), Sibilia (2003, 2005), Schittine (2004), Santos (2006), entre outros.

Compor um blog é um dos fenômenos mais importantes da cultura digital na contemporaneidade (Chassot, 2005). O tema deste trabalho versa sobre um tipo de blog, muito utilizado pelos adolescentes, que funciona como um diário pessoal online, que pode ser acessado livremente na web. Nesse espaço, os jovens contam sobre si e expõem uma parte de seu cotidiano, escrevem seu perfil, poesias, pensamentos, protestos, colocam fotografias e esperam os comentários de quem os lê. Cabe ressaltar que existem outros tipos de blogs, como os de jornalistas, políticos, artistas e demais profissionais que buscam um espaço de expressão e de comunicação.

A proposta deste artigo é refletir sobre a escrita em blogs na constituição do sujeito adolescente, em uma perspectiva psicanalítica. O método de pesquisa utilizado foi o de revisão de literatura, incluindo textos de periódicos e não periódicos, nacionais e internacionais. Inicialmente foram selecionados alguns textos de Freud, em que há referência ao tema da escrita. Em um segundo momento, buscaram-se textos de autores contemporâneos que pesquisam sobre a temática da escrita e sobre a temática da adolescência na psicanálise. Realizou-se uma busca online nas bases de dados Lilacs, SciELO e PsycINFO, no período de abril de 2004 até janeiro de 2007. Além destes textos, foram consultados escritos sobre a internet e os blogs. A busca deste material também se realizou em periódicos e não periódicos, e mediante uma pesquisa online no site $<$ http://pontomidia. com.br/wiki/doku.php?id=blogbrasil>, no mesmo período citado acima.

Portanto, a revisão de literatura partiu do escrever em Freud e seguiu até psicanalistas contemporâneos que trabalham com o tema da escrita. Em seguida, foram assinaladas questões relacionadas às mudanças vividas na adolescência, enquanto evento subjetivo, em um enlace com a escrita. A respeito do escrever na adolescência, tomou-se como base a colocação de Rassial (1997), de que este é o período da escrita e da leitura, idade em que o ler e o escrever mudam de valor de várias maneiras. Nesse momento da vida, em que a palavra dos pais e demais adultos é questionada, os adolescentes precisam experimentar essa outra consistência da língua, que é a da escrita. Por fim, apontam-se algumas considerações sobre a era digital e o ciberespaço, pensando os blogs adolescentes como narrativas do eu na internet.

\section{A escrita em Freud}

Na psicanálise, desde seu surgimento até a atualidade, a escrita sempre ocupou um lugar importante, o que torna sua investigação de grande relevância. Ao longo da revisão das obras de Freud, pode-se notar que o escrever marca o seu percurso, e aparece de formas distintas em alguns de seus textos, por vezes como uma metáfora e até mesmo com o intuito de elucidar o funcionamento do inconsciente.

Nos escritos freudianos sobre a sua clínica, os casos eram expostos na forma de narrativas da cena analítica, na qual o sujeito estava no centro da questão, ao invés de se tratar de um simples relato de enfermidade (Birman, 2001); isso outorgou ao escrito psicanalítico a sua particularidade.

Tomando inicialmente a escrita do próprio Freud, que endereçou muitas cartas a Fliess, percebe-se que a psicanálise teve, desde o seu nascimento, o suporte da escrita. O pai da psicanálise era um exímio escritor: escreveu sobre os casos que atendeu, sobre suas descobertas e suas hipóteses acerca do funcionamento do aparelho psíquico, possibilitando, assim, uma transmissão do campo de saber que ele fundou.

Na carta 52, que Freud (1950/1969e) escreveu a Fliess, surgiram as primeiras alusões a signo, inscrição e transcrição na investigação dos processos psíquicos. Neste documento, há referência a uma retranscrição que o material presente na memória de um sujeito poderia sofrer de tempos em tempos, mediante um processo de reestruturação.

Em um outro momento, em Notas sobre o bloco mágico, Freud (1925/1969d) propôs um enlace entre o aparelho psíquico e a escrita. Nesse texto, apresentou um modelo de aparelho psíquico e o relacionou com a memória. Para tanto, lançou mão de um instrumento chamado bloco mágico. Tal invento seria mais útil que uma folha de papel ou uma lousa na hora de escrever, e as notas nele escritas poderiam ser apagadas com um 
simples gesto manual. O bloco de notas mágico não teria um espaço limitado para a escrita, como acontece em uma folha de papel, e também se distinguiria da escrita com giz em uma lousa, que, apesar de possibilitar a destruição das notas desinteressantes, não permite que traços importantes sejam mantidos. Este novo instrumento, além da possibilidade de ser utilizado repetidas vezes, recebendo novas informações, teria a capacidade de guardar os traços permanentes. Freud comparou este mecanismo do bloco mágico com sua hipótese a respeito do funcionamento do aparelho perceptivo.

No texto Escritores criativos e devaneios, Freud (1908/1969a) demonstrou curiosidade a respeito do escrever, e manifestou um grande fascínio pelo trabalho criativo dos escritores. Lançou mão de alguns pressupostos, relacionando o brincar infantil à criação poética, pois, para ele, tanto a criança que brinca quanto o escritor criativo teriam a possibilidade de criar mundos próprios que Ihes agradassem. Freud questionou, ainda, se seria possível comparar o escritor criativo àquele que costuma"sonhar" acordado, e se haveria alguma semeIhança entre seus escritos e os devaneios. Mais adiante, sugeriu que uma determinada vivência no presente do escritor poderia lhe despertar lembranças de fatos vividos anteriormente, possivelmente na infância, e, a partir destas lembranças, nasceria um desejo que encontraria realização na obra criativa. Assim, uma obra literária seria como um devaneio, que daria continuidade ou substituiria o brincar infantil. Através daquilo que escreve, o autor estaria apresentando suas próprias fantasias.

Em Notas psicanalíticas sobre um relato autobiográfico de um caso de paranoia, Freud (1911/1969b) apoiou sua investigação sobre a paranoia no estudo realizado a partir dos escritos autobiográficos de Schreber; investigou o que o próprio sujeito havia escrito sobre sua doença, realizando uma "leitura-escuta", e buscou analisar os mecanismos psíquicos inconscientes existentes ao longo daquela narrativa.

Freud também dedicou parte de suas investigações aos sonhos, considerando-os elementos decifráveis. Comparou as imagens de um sonho a hieróglifos, fazendo referência ao caráter da escrita, peculiar ao conteúdo inconsciente. Compreende-se que a escrita possui em comum com as formações do inconsciente a característica de ser legível e decifrável (Lacet, 2003).
Como acrescentou Allouch (1995, p.17), o trabalho analítico opera com a hipótese da existência de um sujeito do inconsciente. Ele afirma que "toda a formação do inconsciente é um hieróglifo - no sentido inicial resiste à compreensão imediata, não é transparente e só se deixa ler mediante um trabalho de deciframento".

Nesse sentido, o estudo sobre a escrita adolescente em blogs segue a tradição freudiana, que ensina que uma informação do inconsciente, assim como os atos falhos e os lapsos de linguagem, está no trivial, nas minúcias, nos detalhes. A função interpretante pode se encontrar nesses elementos modestos e corriqueiros.

É interessante destacar, ainda, que as narrativas de jovens chamaram a atenção de Freud, que escreveu à Dra. Hermine Von Hug-Hellmuth sobre o valor do diário, considerando-o uma "pequena joia". Acreditava ele que "tudo é expresso de modo tão encantador, tão natural e tão sério nessas notas despretensiosas que elas não podem deixar de despertar o maior interesse em educadores e psicólogos... é seu dever, julgo eu, publicar o diário. Meus leitores Ihe ficarão gratos"Freud (1915/1969c, p.385). Muitos anos depois, observa-se que a sugestão de Freud - publicar diários - tornou-se uma prática comum entre os adolescentes. A internet permitiu que fosse criada, na atualidade, uma modalidade de diários virtuais: os blogs.

\section{Escrita e transmissão da experiência}

As tecnologias digitais e o ciberespaço, presentes nos tempos atuais, possibilitaram o nascimento de um recente modo de escrita: a escrita online. Os adolescentes escrevem sobre suas vivências íntimas nas páginas dos blogs e elas ficam expostas na rede internacional de computadores. Tais narrativas entrelaçam o privado e o público e apontam para uma busca de expressão dos adolescentes. O que se pode ler nas "entrelinhas" desta escrita de que os adolescentes contemporâneos têm lançado mão? Por que escrever a adolescência em blogs?

O recurso à escrita, ao longo da história da humanidade, tem se apresentado como um suporte importante para a transmissão da experiência. A escrita pode ter a função de legitimar uma experiência e de produzir - ela própria - uma experiência. Benjamin (1992) propôs que a experiência se estabelece no momento em 
que é transmitida, e não quando é vivida. Nas palavras de Kehl (2001, p.22): "é no ato de testemunhar, ou de narrar, ato de fala endereçado a um outro, que o vivido se constitui como experiência". Uma vez que a concepção de experiência compreende a noção de endereçamento, como pontuou Rickes (2003), é no endereçamento que uma experiência alcança tal estatuto, pois há o encontro e a inscrição do outro.

A escrita carrega restos não assimiláveis por parte daquele que escreve. Nesse sentido, busca-se subsídio na ideia de Costa (2001), de que na tentativa de transmissão de algo por meio do escrever, aquele que escreve pode produzir um ato que possui o valor de um registro. Esta escrita produziria efeitos no autor para além daquilo que ele se percebe escrevendo.

A verdade que mais tem sido considerada importante é aquela que está no sujeito, na intimidade - de onde se supõe que venham a fala e a escrita. Sempre se escreveram histórias de vida, porém a ideia de que a vida é uma história faz parte da cultura ocidental. A escrita de diários íntimos, assim como de autobiografias, pode significar a invenção de um novo sentido, como bem apontou Calligaris (1997). Tal prática vai além de uma descrição de atividades do dia a dia de quem escreve, mas pode ser a saída encontrada por alguém que se encontra em uma "encruzilhada íntima" para confessar verdades que, de outro modo, não conseguiria revelar.

O desconhecer-se e o conhecer-se podem acontecer tanto mediante a experiência psicanalítica quanto por meio da escrita. Nessa medida, Bartucci (2001, p.383) propôs "o ato de criação, da escritura, como criação de um sujeito, como lugar psíquico de constituição de subjetividade". Há um lugar que é construído pelo próprio texto criado por aquele que se aventura a escrever. A esse respeito, evoca-se a colocação de Rickes (2002), de que a escrita não é apenas um produto, mas a produtora de um lugar sujeito/autor. Segundo Sousa (1997), a relação do sujeito com a escrita situa-se no espaço da alteridade, do estranho, do desconhecido e, assim, a escrita é uma tentativa de alcançar um lugar. Questiona ainda este autor:"quem mais do que o adolescente precisa disto?" (p. 205), já que ele evidencia um "não lugar" devido à crise identitária que vivencia.

Calligaris (1997), seguindo as ideias lacanianas, 208 pontuou que a verdade está em uma linha ficcional.
Fazer da própria vida uma ficção é o modo ocidental moderno de orientá-la e reorientá-la. Narrar a si mesmo não é diferente de inventar para si mesmo uma vida; assim, por meio da fala e da escrita pode ocorrer a produção de um sujeito, já que o ato autobiográfico, além de contar uma história, constitui a própria história daquele que conta.

O blog adolescente pode ser pensado como uma escrita autobiográfica contemporânea, uma forma de escrever a si mesmo. O adolescente, nesta atividade, pode se reconstruir a partir das questões subjetivas que o afligiram e o colocaram a escrever.

Por meio da escrita, é possível ao sujeito explorar a dimensão do estrangeiro. A adolescência é um tempo de exílio, no qual as fronteiras de um "aqui"e um"lá" são construídas. É esse exílio interior que propicia o nascimento de um sujeito da escrita, que possibilita que um estilo venha a ser construído. É essa condição de exílio que torna possível escrever (Sousa, 1997).

\section{O escrever na adolescência}

A adolescência pode ser compreendida como um evento subjetivo, passagem da infância para a vida adulta, que se inicia com as transformações da puberdade. O sujeito adolescente é aquele que se vê às voltas com as metamorfoses de seu corpo, com as novas situações que the são agora conferidas no mundo dos "grandes", precisando se situar como adulto entre os adultos. O encontro com o real das modificações corporais e com o real do sexo, bem como a reedição inconsciente do conflito edípico, exigem modificações psíquicas do adolescente (Alberti, 2004; Rassial, 1997; Ruffino, 1993).

A necessidade de desligar-se dos pais é um dos feitos psíquicos mais dolorosos para o jovem, segundo Alberti (2002). Ao descobrir o logro da promessa edípica, acontece uma quebra das identificações do adolescente com os pais imaginários da infância, o que o leva a um afastamento destas figuras. A contestação da palavra dos pais e a saída do lar familiar rumo ao laço social levam à necessidade de encontrar outras referências além das parentais, ou seja, o sujeito vê-se diante da exigência de realizar uma nova construção identificatória. Neste momento, os adolescentes lançam mão de algumas estratégias como forma de assegurar uma 
marca de identificação. É nesse contexto que a escrita pode se situar como uma nova língua para a circulação (Lima, 2003; Rassial, 1997) uma vez que a língua do lar nem sempre valerá no espaço público, caberá ao adolescente aprender uma outra língua, que é falada na rua.

O diário tradicional situa um campo simbólico de compartilhamento de um enigma, um lugar de passagem de uma língua a outra, onde o sujeito adolescente pode circular entre a casa dos pais e o grupo de iguais. Nesse sentido, a escrita pode retratar uma mudança de endereço, que é consequência de um conflito relativo ao reconhecimento de um lugar próprio (Costa, 2001).

Nesta travessia, em que ocorre uma perda do lugar desde onde o sujeito se significava, a escrita pode funcionar como um veículo que permite ao adolescente expressar o que não está conseguindo comunicar de uma outra maneira, constituindo, assim, um recurso de linguagem em um código social, discursivo.

Outro ponto importante, como foi citado anteriormente, é a necessidade que se apresenta ao adolescente de reapropriar-se do próprio corpo. As mudanças da puberdade impõem mudanças ao corpo da infância, que tem seus antigos contornos modificados sem que haja algum controle. Há um luto a ser feito pelo corpo infantil perdido e, também, um sentimento de estranhamento do jovem em relação ao seu "novo" corpo, que na verdade nunca deixou de ser seu. Énecessário reconstruir uma imagem corporal, como se o corpo precisasse ser novamente escrito por significantes (Backes, 2004).

Há uma reedição do estágio do espelho na adolescência. Frente às modificações no estatuto e no valor do corpo, o sujeito necessita reapropriar-se de sua imagem; assim, ocorre uma confirmação da sua identificação inicial - pré-sexuada. Assim como no estágio do espelho foi fundamental que o olhar do outro assegurasse ao bebê que a imagem refletida no espelho era a sua, algo parecido ocorre na adolescência. Surge a demanda pelo olhar de um "novo" outro, de um olhar que confirme o novo estatuto de sua imagem como desejável e desejante (Giongo, 2004; Rassial, 1999).

$\mathrm{Na}$ mudança de endereço que acontece na passagem adolescente, a posição infantil e os laços familiares são deixados pelo sujeito para que este possa inclinar-se, em outra posição, aos laços em que procurará inserir a sua atividade pulsional (Oliveira, 2004). Há uma busca do adolescente por criar novas significações e novas referências, isto é, compor um novo elo entre o discurso (o outro) e a pulsão. As modificações na instância do outro e na imagem do corpo levam o adolescente à empreitada de recompor a imagem especular, o estágio do espelho, reinscrevendo voz e olhar (Poli \& Becker, 2004).

Esses objetos pulsionais constituem um suporte do corpo infantil para o corpo adulto, e o adolescente pode encontrar na escrita, bem como na música, maneiras de se situar em relação ao seu desamparo corporal, já que nessas duas experiências podem ser encontrados os traços que situam esses dois objetos pulsionais privilegiados neste momento da vida (Costa, 2004).

Nesse sentido, será que as montagens presentes nos blogs podem ser pensadas como um apelo à construção de imagens para a tarefa de delinear contornos que possibilitem ao sujeito adolescente existir? Escrever nas páginas online de um blog é diferente de escrever nas folhas de papel de um diário tradicional; assim, surge o seguinte questionamento: como será esta travessia adolescente quando a escrita se dá no ciberespaço?

\section{A busca de um lugar no laço social}

Na adolescência, é a estrutura subjetiva que está em causa, devido ao abalo sofrido pelo imaginário. 0 jovem precisa emergir e sustentar-se, e necessita de outras referências além das parentais. Nesse contexto de construção de novos ideais, a principal referência se torna o grupo de amigos: os pares serão as grandes fontes de identificação deste momento. Os adolescentes que compõem blogs compartilham desta prática com o grupo de amigos; é uma atividade que os reúne e para a qual criaram um código cifrado de escrita comum apenas entre eles. Esta língua digital particular aos"blogueiros" acaba excluindo quem não tem conhecimento da mesma.

Uma característica bastante notável dos grupos adolescentes da atualidade é o fato de se organizarem em torno de um laço fraterno socializante, seja para lutar contra o tédio do dia a dia, seja para buscar expres- 
sar certo ideário, e eles estão geralmente envolvidos com determinadas atividades culturais (Coutinho, 2005). Tais atividades cotidianas compartilhadas podem revelar uma tentativa conjunta de elaborar impasses relativos ao laço social contemporâneo. A turma adolescente pode funcionar como garantia de reconhecimento de traços identificatórios dos quais o sujeito que deixa a infância não se sente seguro, e também como campo de novas identificações exogâmicas - lembrando que a adolescência é o período da primazia das grandes formações fraternas (Kehl, 2000).

A composição do diário virtual é dividida com os pares, e na maioria dos blogs há uma lista citando blogs de outros amigos passíveis de serem acessados, de modo que se forma uma rede interligada. Outra característica desta prática é que aquele que produz o blog costuma pedir aos visitantes de sua página que deixem comentários sobre aquilo que ele escreveu.

\section{Blogs: narrativas do eu na internet}

A era digital transformou a relação com a cultura escrita, já que, com a web, surgiu uma nova forma de transmissão dos textos. O historiador Chartier (2002) nomeou esta evolução nos meios eletrônicos como revolução digital, que, por sua vez, deu origem a uma revolução no modo de ler e escrever. Nesse contexto, os textos são dados à leitura em um mesmo suporte, a tela do computador, que parece oferecer liberdade, maleabilidade e possibilidades nunca antes vividas pelos escritores. Surgiu então uma nova forma de escrita e leitura, agora online.

A digitalização promoveu uma grande transformação e deu um novo impulso ao texto e à própria leitura. As mensagens digitais e a amplitude do ciberespaço têm exercido um papel fundamental nas transformações que vêm acontecendo na comunicação e na informação, mas a"virtualização", além disso, ultrapassa a informatização. Uma marca presente na virtualização é o trânsito do interior ao exterior e vice-versa. Segundo Lévy (1996), esta passagem pode ser chamada de"efeito Moebius", que acontece nas relações privado/público, autor/leitor, entre outras. Os limites não são mais determinados, e os lugares e tempos se interpõem.

Cabe lembrar aqui a colocação de Lacan (1998)

210 sobre a constituição do sujeito: algo também acontece, como na fita de Moebius, de modo que não há distinção entre a banda de fora e a banda de dentro, nem fronteiras determinadas entre o interior e o exterior, entre o sujeito e o outro. Nesse sentido, o ciberespaço aponta para algo que já estava presente. Vê-se com a recente tecnologia algo estruturante do sujeito, ou seja, é na relação com o outro que se dá algo próprio.

No caso dos blogs, surge um novo elemento que não havia nos diários e agendas tradicionais: o ciberespaço. Essa rede sem fronteiras determinadas é um espaço novo, constituído pela interconexão de computadores do mundo inteiro. A ligação entre humanos de todos os horizontes em um só tecido aberto e interativo produz uma situação totalmente inédita, na qual leitura e escrita mudam de papel (Lévy, 1999).

A comunicação eletrônica livre e espontânea permite que qualquer um que deseje possa colocar suas próprias criações a circular pela web. É o caso do blog, que se tornou uma ferramenta contemporânea muito utilizada por aqueles que desejam publicar algo no espaço cibernético. Além dos blogs criados por adolescentes para narrarem suas vidas, muitos jornalistas, políticos, artistas e demais profissionais criam blogs pessoais para interagir com um público leitor.

A respeito dos blogs adolescentes, buscam-se subsídios nos estudos de Turkle (1989), que observou que muitos adolescentes fazem uso dos meios eletrônicos como uma tela para expressar o que estão vivenciando, e utilizam o computador como uma máquina para construírem seus mundos. Por meio de experiências com o computador, o jovem pode encontrar uma forma de refletir sobre si mesmo.

Como acrescentou Rodulfo (1997), os meios teletecnomediáticos parecem funcionar como meios de comunicação, mas tratam-se, além disso, de meios de invenção da subjetividade. Outra característica dos meios teletecnomediáticos é abalar a separação entre realidade e ficção, já que para o adolescente os meios fazem parte da realidade, são a própria realidade.

Muitos blogs estão no meio do caminho entre realidade e ficção, como colocou Schittine (2004). O blog pessoal trata de uma escrita do eu na web e é chamado de diário íntimo na internet, pois muitos "blogueiros" narram sua intimidade nesse espaço. O elemento novo presente nos blogs é a suposição da presença de um 
público leitor: aquele que escreve um blog escreve para ser lido. Assim, do papel para a tela, o diário que antes pertencia à esfera íntima abre-se para a pública.

Lemos (2002) chamou os blogs de "webdiários" ou "ciberdiários", e apontou para a característica marcante dos "blogueiros", que é a de escreverem sobre si. Os blogs são, ao mesmo tempo, pessoais e públicos, e versam sobre a vida cotidiana de quem os escreve, tratando-se de uma escrita na qual há uma preocupação com a maneira como o eu será apresentado no ciberespaço. E, assim, a vida privada pode ser transformada em um espetáculo aos olhos daqueles que navegam pela internet.

Essa visibilidade espetacular que pode ser proporcionada pelos diários virtuais aponta para uma questão contemporânea que diz respeito à supervalorização da imagem. Há uma legião de indivíduos desamparados, cujo reconhecimento social fica subordinado inteiramente a uma visibilidade espetacular, que atende a uma ordem na qual o único agente do espetáculo é ele mesmo (Kehl, 2004).

A dimensão pública característica dos blogs é importante para o adolescente, que clama pelo olhar do outro e busca um lugar no laço social, mas é importante lembrar que uma escrita espetacularizada nos blogs é diferente de uma escrita endereçada ao outro na busca de um olhar que venha a firmar uma identidade em construção. Estas são duas vertentes possíveis dessa escrita online.

\section{Considerações Finais}

A escrita em blogs pode ser pensada como um novo meio de expressão do inenarrável encontrado pelos adolescentes contemporâneos. Mesmo que o suporte da escrita tenha passado das folhas de papel para páginas online, o conteúdo destas narrativas continua sendo relacionado às vivências pessoais daquele que escreve.

No entanto, o que antes ficava restrito ao mundo privado passou à esfera pública. Os sonhos, a intimidade e a vida pessoal dos jovens "blogueiros" são publicados no ciberespaço. Esta nova forma de escrita, que entrelaça o privado e o público, vem sendo marcante na atuali- dade. O "blogueiro" escreve sobre sua vida, utiliza imagens como fotografias, letras de músicas, poesias que falam sobre si, em uma provável tentativa de que esta produção Ihe ajude a transpor, ou seja, passar de um lugar ao outro. Nesse sentido, os adolescentes, que estão na travessia da família rumo ao laço social, podem encontrar no blog um meio para esboçar essa passagem.

Essas narrativas do eu no ciberespaço podem possibilitar uma nova forma de vida. Compor um blog pode ser um ato que produz o sujeito a partir de um fazer que ele mesmo desconhece. À medida que o adolescente apresenta-se de forma diferente, pode ter uma vida diferente. Ao escrever no blog, estaria construindo uma posição desde a qual falar. Há um sujeito que irá revelar-se após o ato da escrita. Há sempre uma surpresa em revelar a si mesmo o que se desconhece. Criar um blog pode representar uma experiência subjetiva de criação, uma experiência que permite ao sujeito ser outro.

Outra questão interessante que surge com a escrita online é a possibilidade de ligação do "blogueiro" com o grupo de amigos por meio de uma rede que interliga os blogs. Esta prática virtual apresenta como uma de suas características o diálogo, a interatividade entre aquele que escreve e seus supostos leitores. Pode-se perceber que a comunicação acontece de forma rápida e veloz; a escrita é quase simultânea à sua publicação no ciberespaço. O "blogueiro"espera e solicita os comentários sobre aquilo que escreveu, o que parece vir ao encontro da necessidade adolescente de reconhecimento.

Cabe destacar que o blog está sempre sendo construído, assim como o sujeito adolescente está vivendo um momento de constituição de si mesmo. A composição de um blog remete à imagem da montagem de um puzzle, pois os adolescentes, nessas páginas online, vão pouco a pouco juntando pedacinhos de suas vidas.

Sugere-se a importância de que novas pesquisas venham a ser desenvolvidas sobre as recentes tecnologias que envolvem a internet e a escrita online, para ampliar a investigação sobre este fenômeno, que é tão novo e que ainda vive tantas mudanças. 


\section{Referências}

Alberti, S. (2002). O adolescente e seu pathos. Psicologia USP, 13 (2), 183-202.

Alberti, S. (2004). O adolescente e o outro. Rio de Janeiro: Jorge Zahar.

Allouch, J. (1995). Letra a letra: transcrever, traduzir, transliterar. Rio de Janeiro: Campo Matêmico.

Backes, C. (2004). A reconstituição do espelho. In A. M. Costa, C. Backes, V. Rilho \& L. F. L. Oliveira (Orgs.), Adolescência e experiência de borda (pp.29-41). Porto Alegre: UFRGS.

Bartucci, G. (2001). Entre o mesmo e o duplo, inscreve-se a alteridade. Psicanálise freudiana eescrituraborgiana. In G. Bartucci (Org.), Psicanálise, literatura e estéticas de subjetivação (pp.369-385). Rio de Janeiro: Imago.

Benjamin, W. (1992). O Narrador. In Sobre arte, técnica, linguagem e política. Lisboa: Relógio D’Água Editores.

Birman, J. (2001). A escrita em psicanálise. In G. Bartucci (Org.), Psicanálise, literatura e estéticas de subjetivação, (pp.185-196). Rio de Janeiro: Imago.

Calligaris, C. (1997). Verdades de autobiografias e diários íntimos. Recuperado em maio 5, 2006, disponível em www.cpdoc.fgv.br/revista/arq/236.pdf

Chartier, R. (2002). Os desafios da escrita. São Paulo: UNESP.

Chassot, A. (2005). Escrever diários como uma forma de colecionismo. Episteme, 10 (20), 55-70.

Costa, A. M. (2001). Corpo e escrita: relações entre memória e transmissão de experiência. Rio de Janeiro: Relume Dumará.

Costa, A. M. (2004). A transicionalidade na adolescência. In A. M. Costa, C. Backes, V. Rilho \& L.F.L. Oliveira (Orgs.), Adolescência e experiência de borda (pp.165-193). Porto Alegre: UFRGS.

Coutinho, L. G. (2005). A adolescência na contemporaneidade: ideal cultural ou sintoma social? Revista Pulsional, 18 (181), 16-23.

Freud, S. (1969a). Escritores criativos e devaneios. In J. Strachey (Ed.), Edição standard brasileira das obras psicológicas e completas de Sigmund Freud (Vol. 9, pp.147-158). Rio de Janeiro: Imago (Originalmente publicado em 1908).

Freud, S. (1969b). Notas psicanalíticas sobre um relato autobiográfico de um caso de paranóia. In J. Strachey (Ed.) Edição standard brasileira das obras psicológicas e completas de Sigmund Freud (Vol. 12, pp.15-108). Rio de Janeiro: Imago (Originalmente publicado em 1911).

Freud, S. (1969c). Breves escritos: carta à dra. Hermine von Hug-Hellmuth. In J. Strachey (Ed.), Edição standard brasileira das obras psicológicas e completas de Sigmund Freud (Vol. 14, p.385). Rio de Janeiro: Imago (Originalmente publicado em 1915).

Freud, S. (1969d). Uma nota sobre o bloco mágico. In J. Strachey (Ed.), Edição Standard brasileira das obras psicológicas e completas de Sigmund Freud (Vol. 19, pp.283-290). Rio de Janeiro: Imago (Originalmente publicado em 1925).

Freud, S. (1969e). Extratos dos documentos dirigidos a Fliess: carta 52. In J. Strachey (Ed.), Edição Standard brasileira das obras psicológicas e completas de Sigmund Freud (Vol. 1, pp.317-324). Rio de Janeiro: Imago. (Originalmente publicado em 1950).

Giongo, A. L. (2004). Diga-me com quem andas. In A.M. Costa, C. Backes, V. Rilho \& L.F.L. Oliveira (Orgs.), Adolescência e experiência de borda (pp.89-99). Porto Alegre: UFRGS.

Kehl, M. R. (2000). Função fraterna. Rio de Janeiro: Relume-Dumará

Kehl, M. R. (2001). Prefácio. In A. Costa. Corpo e escrita: relações entre memória e transmissão de experiência (pp.11-24). Rio de Janeiro: Relume-Dumará.

Kehl, M. R. (2004). O espetáculo como meio de subjetivação. In E. Bucci \& M. R. Kehl. Videologias (pp.43-62). São Paulo: Bointempo.

Lacan, J. (1998). Escritos. Rio de Janeiro: Jorge Zahar.

Lacet, C. (2003). Considerações sobre a letra e a escrita na clínica psicanalítica. Estilos da Clínica, 8(14), 50-59.

Lemos, A. (2002). A arte da vida: diários pessoais e webcams na internet. Anais do XXV Congresso Brasileiro de Ciências da Comunicação. Salvador. Recuperado em junho 20, 2006, disponível em http://reposcom.portcom.intercom. org.br/dspace/bitstream/1904/18835/1/2002_NP8 lemos.pdf

Lévy, P. (1996). O que é virtual? São Paulo: Editora 34.

Lévy, P. (1999). Cibercultura. São Paulo: Editora 34.

Lima, M. C. (2003). Corpo em escrita: considerações acerca da linguagem alegórica como dispositivo de construção do sujeito adolescente. In I. Costa, A. Holanda, F. Martin \& M. Tafuru (Orgs.), Ética, linguagem e sofrimento (pp.65-73). Brasília: ABRAFIPP.

Oliveira, L. F. L. (2004). A representação e a afirmação subjetiva: a passagem da pulsão pela língua na adolescência. In A. M. Costa, C. Backes, V. Rilho \& L.F.L. Oliveira (Orgs.), Adolescência e experiência de borda (pp.73-87). Porto Alegre: UFRGS.

Poli, M. C. \& Becker, A. L. (2004). Adolescência: uma abordagem na psicanálise lacaniana. In M. Macedo. Adolescência e psicanálise: intersecções possiveis (pp.133-146). Porto Alegre: EDIPUCRS.

Rassial, J. J. (1997). A Passagem adolescente: da família ao laço social. Porto Alegre: Artes e Ofício.

Rassial, J. J. (1999). O adolescente e o psicanalista. Rio de Janeiro: Companhia de Freud.

Recuero, R. (2003). Warblogs: os weblogs, o jornalismo online e a guerra no Iraque. Verso e Reverso, 37, 57-76.

Rickes, S. (2002). A escritura como cicatriz. Educação e Realidade, 27 (2), 51-71. 
Rickes, S. (2003). Escrita da clínica e transmissão da psicanálise. Revista da APPOA: Variantes da Cura, 25 (23), 119-133.

Rodulfo, R. (1997). Um novo ato psíquico: a inscrição ou a escrita do nós na adolescência. In Associação Psicanítica de Porto Alegre. Adolescência entre o passado e o futuro (pp.271-280). Rio de Janeiro: Artes e Ofício.

Ruffino, R. (1993). Sobre o lugar da adolescência na teoria do sujeito. In C.R. Rappaport (Org.), Adolescência abordagem psicanalítica (pp.25-57). São Paulo: EPU.

Santos, R. P. (2006). Invenção possível de si num espaço virtual. Narrar - Construir -Interpretar, 30, 145-151.

Schittine, D. (2004). Blog: comunicação e escrita íntima na internet. Rio de Janeiro: Civilização Brasileira.

Sibilia, P. (2003). Os diários íntimos na internet e a crise da interioridade psicológica. In A. Lemos \& P. Cunha (Org.),
Olhares sobre a cibercultura (pp.139-152). Porto Alegre: Editora Sulina.

Sibilia, P. (2005). A vida como relato na era do fast-forward e do real time: algumas reflexões sobre o fenômeno dos blogs. Revista de Biblioteconomia e Comunicação, 11 (2), 35-51.

Sousa, E. (1997). O eus nos textos: escrito de adolescentes. In Associação Psicanalítica de Porto Alegre. Adolescência entre o passado e o futuro (pp.203-211). Rio de Janeiro: Artes e Ofício.

Turkle, S. (1989). O segundo eu: os computadores e o espírito humano. Lisboa: Editorial Presença.

Recebido em: 7/8/2007

Versão final reapresentada em: 30/10/2008

Aprovado em: 10/12/2008 
